\title{
Ultra-High Field NMR and MRI-The Role of Magnet Technology to Increase Sensitivity and Specificity
}

\author{
Ewald Moser ${ }^{1,2 *}$, Elmar Laistler ${ }^{1,2}$, Franz Schmitt ${ }^{3}$ and Georg Kontaxis ${ }^{4}$ \\ ${ }^{1}$ Center for Medical Physics and Biomedical Engineering, Medical University of Vienna, Vienna, Austria, ${ }^{2}$ High-field MR \\ Center, Medical University of Vienna, Vienna, Austria, ${ }^{3}$ Lakeside Imaging/e, Quetzin, Plau am See, Germany, ${ }^{4}$ Max F. Perutz \\ Laboratories, Department of Structural and Computational Biology, Center for Molecular Biology, University of Vienna, \\ Vienna, Austria
}

"History, of course, is difficult to write, if for no other reason, than that it has so many players and so many authors." - P. J. Keating (former Australian Prime Minister)

OPEN ACCESS

Edited by:

Evren Özarslan,

Linköping University, Sweden

Reviewed by:

Alexander Rauscher,

University of British Columbia, Canada

Pierre Pugnat,

UPR3228 Laboratoire National des

Champs Magnetiques Intenses

(LNCMI), France

${ }^{*}$ Correspondence:

Ewald Moser

ewald.moser@meduniwien.ac.at

Specialty section:

This article was submitted to

Biomedical Physics,

a section of the journal

Frontiers in Physics

Received: 08 March 2017

Accepted: 02 August 2017

Published: 17 August 2017

Citation:

Moser E, Laistler E, Schmitt F and

Kontaxis G (2017) Ultra-High Field

NMR and MRI-The Role of Magnet Technology to Increase Sensitivity and

Specificity. Front. Phys. 5:33.

doi: 10.3389/fphy.2017.00033
Starting with post-war developments in nuclear magnetic resonance (NMR) a race for stronger and stronger magnetic fields has begun in the 1950s to overcome the inherently low sensitivity of this promising method. Further challenges were larger magnet bores to accommodate small animals and eventually humans. Initially, resistive electromagnets with small pole distances, or sample volumes, and field strengths up to $2.35 \mathrm{~T}$ (or $100 \mathrm{MHz}{ }^{1} \mathrm{H}$ frequency) were used in applications in physics, chemistry, and material science. This was followed by stronger and more stable (Nb-Ti based) superconducting magnet technology typically implemented first for small-bore systems in analytical chemistry, biochemistry and structural biology, and eventually allowing larger horizontal-bore magnets with diameters large enough to fit small laboratory animals. By the end of the 1970s, first low-field resistive magnets big enough to accommodate humans were developed and superconducting whole-body systems followed. Currently, cutting-edge analytical NMR systems are available at proton frequencies up to 1 $\mathrm{GHz}\left(23.5 \mathrm{~T}\right.$ ) based on $\mathrm{Nb}_{3} \mathrm{Sn}$ at $1.9 \mathrm{~K}$. A new $1.2 \mathrm{GHz}$ system (28 $\mathrm{T}$ ) at $1.9 \mathrm{~K}$, operating in persistent mode but using a combination of low and high temperature multi-filament superconductors is to be released. Preclinical instruments range from small-bore animal systems with typically $600-800 \mathrm{MHz}(14.1-18.8 \mathrm{~T})$ up to $900 \mathrm{MHz}$ $(21 \mathrm{~T})$ at $1.9 \mathrm{~K}$. Human whole-body MRI systems currently operate up to $10.5 \mathrm{~T}$. Hybrid combined superconducting and resistive electromagnets with even higher field strength of $45 \mathrm{~T} d c$ and $100 \mathrm{~T}$ pulsed, are available for material research, of course with smaller free bore diameters. This rather costly development toward higher and higher field strength is a consequence of the inherently low and, thus, urgently needed sensitivity in all NMR experiments. This review particularly describes and compares the developments in superconducting magnet technology and, thus, sensitivity in three 
fields of research: analytical NMR, biomedical and preclinical research, and human MRI and MRS, highlighting important steps and innovations. In addition, we summarize our knowledge on safety issues. An outlook into even stronger magnetic fields using different superconducting materials and/or hybrid magnet designs is presented.

Keywords: NMR, MRI, MRS, magnet technology, superconductors, gradients, sensitivity

\section{BACKGROUND}

Although there have been earlier attempts by physicists to measure the gyromagnetic ratio of various materials using nuclear magnetic resonance $(\mathrm{NMR})^{1}$, what we call NMR and later magnetic resonance spectroscopy (MRS) and imaging (MRI) today has been commercially available only from the 1950s on. This technology was based on simultaneous discoveries by Felix Bloch at Stanford and Edward Purcell at Harvard, who were jointly awarded the Nobel prize in physics already in 1952. In addition, a number of Nobel prizes related to NMR were given to physicists working in various related fields thereafter:

- A. Kastler (1966) for the "double resonance method,"

- J. H. van Vleck (1977) for a theory of dia- and paramagnetism,

- N. Bloembergen (1981) for relaxation, motion and the BPP theory of relaxation,

- H. G. Dehmelt (1989) for pure nuclear quadrupole resonance,

- N. F. Ramsey (1989) for the concept of chemical shift; spin inversion $\left(180^{\circ}\right.$ pulse), and negative (spin) temperature.

Nobel prizes in Chemistry were subsequently awarded to

- R. R. Ernst (1991) for his contributions to the development of the methodology of high resolution nuclear magnetic resonance (NMR) spectroscopy,

- K. Wuethrich $(2002,50 \%)$ for his development of nuclear magnetic resonance spectroscopy for determining the three-dimensional structure of biological macromolecules in solution,

\footnotetext{
Abbreviations: $B_{0}$, magnetic flux density (magnetic field strength); BPP, Bloembergen-Purcell-Pound theory of relaxation; CEST, Chemical Exchange Saturation Transfer; CRNM, European Center for High Field NMR; cw, continuous wave; dc, direct current; ECG, electro-cardiography; EPI, echoplanar imaging; FDA, Food and Drug Administration; fMRI, functional magnetic resonance imaging; $\gamma$, gyromagnetic ratio; G, gradient; GE, General Electric; GEMS, General Electric Medical Systems; GRAPPA, generalized autocalibrating partially parallel acquisitions; $H_{c}$, critical field; $H_{c 2}$, upper critical field; HTS, high temperature superconductor; $I_{c}$, critical current; IGC, Intermagnetics General Corporation; MRI, magnetic resonance imaging; MRS, magnetic resonance spectroscopy; MRSI, magnetic resonance spectroscopic imaging; NIH, National Institute of Health; NMR, nuclear magnetic resonance; OI, Oxford Instruments; OMT, Oxford Magnet Technology; PNS, peripheral nerve stimulation; pTx, parallel transmission; RF, radio-frequency; $S A R$, specific absorption rate; sc, superconductor; SENSE, sensitivity encoding; SMT, Siemens Magnet Technology; SNR, signal-to-noise ratio; $S R$, slew rate; $T_{2}$, spin-spin relaxation time; $T_{c}$, critical temperature; UHF, ultra-high field.
}

\footnotetext{
${ }^{1}$ Due to the unfavorable political situation and war time, the Western scientific communities did not acknowledge that Lazarev and Schubnikov measured nuclear magnetism in solid hydrogen already in 1937 [1], and also discovered type 2 superconductors.
}

and, finally, the Nobel prize in Medicine or Physiology to

- P. C. Lauterbur and Sir P. Mansfield (jointly 2003) for their discoveries concerning magnetic resonance imaging.

Furthermore, other scientific achievements have been instrumental in the development of appropriate superconducting magnets, and were recognized by Nobel prizes in physics awarded to

- H. Kammerlingh Onnes (1913) for his investigations of the low-temperature behavior of matter, leading to a method to produce liquid Helium,

- J. Bardeen, L. N. Cooper, and J. R. Shrieffer (1972) for their development of the so-called BCS theory, the theory of the superconducting state,

- J. G. Bednorz and K. A. Mueller (1987) for their groundbreaking discovery of high-temperature (ceramic) superconductors,

- A. A. Abrikosov, V. L. Ginzburg, and A. L. Legget (2003) for pioneering contributions to the theory of superconductors and superfluids.

Historically, we may split the technological development, particularly of high and ultra-high field magnets, into four distinct periods:

A) Resistive electromagnets-with the design goals of increasing field strength, field stability improvement, and cutting operating costs

B) Permanent magnets (to be used at all times, without the need for an electrical power supply) providing low resolution at low cost

C) Superconducting electromagnets-the golden age of NMR, MRS, and MRI

D) Hybrid magnets-ever higher static magnetic fields causing stability and homogeneity problems again.

Based on the various (and sometimes conflicting) requirements and developments in magnet technology, including field stabilization, shimming, RF-coil design and field gradient coils, three distinct areas of research have branched out and have developed independently since:

1) Analytical NMR-determination of structure and dynamics of small organic molecules and large biological macromolecules using small vertical-bore $(2-10 \mathrm{~cm})$, ultra-high field magnets (currently up to $1.2 \mathrm{GHz} / 28.2 \mathrm{~T}$ )

2) Biomedical and preclinical MRI and MRS-animal research using horizontal medium bore size (10-40 $\mathrm{cm}$ ), and ultra-high field magnets (currently up to 900 $\mathrm{MHz} / 21.1 \mathrm{~T})$ 
3) Human head only (60-70 $\mathrm{cm}$ bore) and whole-body (80-125 $\mathrm{cm}$ bore) MRI and MRS-in clinical diagnostics and research ranging between $0.2 \mathrm{~T}$ and $10.5 \mathrm{~T}$.

The signal-to-noise ratio (SNR) of an NMR experiment depends strongly on the applied magnetic field $\mathrm{B}_{0}$ and thus on the Larmor frequency $\omega=\gamma^{*} \mathrm{~B}_{0}$, where $\gamma$ is the gyromagnetic ratio of the nucleus excited (=detected) by the pulse sequence applied. This is typically hydrogen in clinical MRI. In the case of heteronuclei, however, sensitivity can be greatly enhanced through polarization transfer methods, which is exploited to great advantage in spectroscopic techniques in-vitro (in chemical and bio-chemical applications) as well as in-vivo. In this case SNR prop. $n^{*} \gamma_{e}^{*} \operatorname{sqrt}\left(\gamma_{d}^{3 *} B_{0}^{3 *} t\right)$, where $\gamma_{e}$ is the gyromagnetic ratio of the nucleus excited and $\gamma_{\mathrm{d}}$ of the nucleus detected by the pulse sequence applied. In any case, $\mathrm{B}_{0}$ is the most essential parameter to boost SNR.

The achievable signal in an MR experiment is proportional to the equilibrium magnetization $M_{0}$ times the Larmor frequency $\omega_{0}$, both of which are linearly proportional to the magnetic flux density $B_{0}$ (field strength), therefore leading to a dependence of the signal in $B_{0}{ }^{2}$.

One main noise source is the RF system for the detection of the signal, showing a frequency dependence in $\omega_{0}^{1 / 2}$ and, hence, $B_{0}^{1 / 2}$ due to the skin depth effect. The other main noise source is the sample itself, exhibiting a dependence in $B_{0}{ }^{2}$ due to induced eddy currents in the (conductive) tissue. Therefore, the SNR of the MR experiment is increasing with (i) the magnetic flux density $B_{0}$ (field strength), according to

$$
\frac{\text { signal }}{\sqrt{\text { noise }}} \propto \frac{B_{0}^{2}}{\sqrt{\alpha B_{0}^{1 / 2}+\beta B_{0}^{2}}},
$$

scaling with $B_{0}$ for a lossless RF coil and a lossy conductive sample $(\alpha \rightarrow 0)$, and with $B_{0}^{7 / 4}$ for a lossy coil and a lossless non-conductive sample $(\beta \rightarrow 0)$.

Additionally, other parameters and factors contribute to the experiment's sensitivity as well. This includes (ii) RF coil design for improved coupling of the sample's spin system to the RF coil by sample-size- and shape-matched coil geometry (e.g., flexible coil arrays in human studies), as well as minimized losses in the RF coil, achieving sample-dominated noise through the choice of size and/or cooling of the coil, and sometimes also cooling of the preamplifier. Furthermore, the (iii) relaxation properties of the sample may be optimized to increase SNR or contrast. Also, (iv) RF-pulse sequences may be optimized for particular experiments, enabling faster scanning, higher spectral or spatial resolution, featuring particular contrast modules and thus improving specificity (most often at the cost of sensitivity). Enhanced (v) polarization of the spin system even beyond the natural Boltzmann distribution can be achieved via spin transfer from electrons to nearby nuclei, dynamic nuclear polarization, or application of polarized gases (in vivo). An interesting alternative (vi) to improve the detection sensitivity at very low field are quantum detectors such as SQUID (Superconducting Quantum Interference Device) [2, 3]. They work in the presence of metallic objects and makes imaging possible in the presence of large susceptibility. Though currently limited to ultra-low fields this technique may hold great potential for future interesting applications.

However, it is the magnetic flux density $B_{0}$ ("field strength"), that determines the initial Boltzmann population and the Larmor frequency of the nuclear spins, which are relevant in all fields and applications of NMR, and it is therefore the focus of this review.

Already, developments of ultra-high field hybrid MR systems (resistive and superconducting) are in progress [4, 5], providing up to 45 Tesla (with $3 \mathrm{~cm}$ bore size), and which are used in material research [6]. To employ such high fields for analytical NMR or animal studies would require further improvements in field stability and homogeneity for larger bore diameters, as well as a significant reduction in costs for the magnet itself, installation and running costs. Currently, a $14 \mathrm{~T}$ magnet (83 $\mathrm{cm}$ warm bore $)^{2}$ is designed for the German Cancer Centre, Heidelberg, Germany. Furthermore, a conceptual design for a $20 \mathrm{~T}$ human head magnet $(68 \mathrm{~cm}$ warm bore, i.e., without gradient coil; homogeneity yet unknown) as well as a conceptual study toward a $60 \mathrm{~T}$ dc magnet (bore size and homogeneity yet unknown) is underway at the National High Magnetic Field Laboratory at Florida State University, Tallahassee, USA [6].

The dissipationless superconductivity only occurs below a certain critical current which is a function of the magnetic field and temperature, and this critical current is strongly dependent upon the metallurgical state of the superconducting material. It is important to note that a wire in the superconducting state can have a non-zero resistivity, and this dissipative state shall not be reached in a superconducting coil. If this occurs and the energy dissipation cannot be evacuated, the superconductor can quench, i.e., transiting to the normal state via a thermal runaway.

The superconducting parts of most current magnets are composed of type II superconductors like niobium-titanium (Nb-Ti). This material has a critical temperature of $10 \mathrm{~K}$ and can superconduct at up to about $15 \mathrm{~T}$ (upper critical field $H_{c 2}$ ). More expensive magnets can be made of niobium-tin $\left(\mathrm{Nb}_{3} \mathrm{Sn}\right)$. These have a $\mathrm{T}_{\mathrm{c}}$ of $18 \mathrm{~K}$. When operating at $4.2 \mathrm{~K}$ (the boiling point of liquid helium) they are able to withstand a much higher magnetic field strength, up to $20 \mathrm{~T}$. Unfortunately, it is far more difficult to produce the required filaments from this material which is rather brittle. This is why sometimes a combination of $\mathrm{Nb}_{3} \mathrm{Sn}$ for the high-field sections and $\mathrm{Nb}$-Ti for the lower-field sections is used [7].

When the magnetic field is further increased, the critical temperature drops below $4.2 \mathrm{~K}$ and the boiling point of liquid Helium has to be lowered to $\sim 1.9-2 \mathrm{~K}$ by reducing the pressure to 10-20 mbar. Through this technique the superconductivity of $\mathrm{Nb}_{3} \mathrm{Sn}$ can be extended to around 23-25 $\mathrm{T}$.

Only recently, hybrid magnets help to overcome this limit, by combining brittle superconductors like $\mathrm{Nb}_{3} \mathrm{Sn}$ (for the outer magnet sections) and ceramic-based high temperature superconductors (HTS) for the inner parts [6]. Still, despite being HTS, the production of high fields with such superconducting materials requires to operate them at a temperature significantly

${ }^{2} 200$ tons unshielded, stored energy $660 \mathrm{MJ}$; courtesy M.E. Ladd and ASG Superconductors s.p.a., Genova, Italy. 
lower than Tc and in general, the temperature of liquid helium is chosen. This may change with the development of dry cryogenics.

In Figure 1, the increase of magnetic flux density $B_{0}$ (in Tesla) over time is depicted for all types of commercially available magnets, i.e., in analytical NMR (left), preclinical MRI (middle), and human MRI (right) at their first commercial availability. Please note the rather similar time slopes for analytical and preclinical NMR, just shifted in time, due to the use of similar superconducting wire material, particularly $\mathrm{Nb}-\mathrm{Ti}$ and $\mathrm{Nb}_{3} \mathrm{Sn}$, for the various NMR and MRI systems. Due to commercial and legal restraints, i.e., costs (magnet size) and safety issues, human MRI magnets show a somewhat lower slope.

In the following, we will be discussing critical steps and features in magnet and gradient development. In order to enable some transparency, we decided to list novel magnets (field strength and bore diameter) only in case they have been successfully applied in the field (or at the time of a first publication). In addition, we do not explicitly list further developments at the same field strength, e.g., actively shielded, or ultra-shielded refrigerated magnets, as they typically follow initial development within 3-10 years (depending on bore diameter).

\section{RESISTIVE ELECTROMAGNETS, THE BEGINNING OF ANALYTICAL NMR}

Early commercialization of NMR was initiated by R. Varian, based on F. Bloch's discovery of NMR in liquids [8], with the use of resistive electromagnets and employing continuous-wave (cw) sweep techniques $[9,10]$. Varian Inc. provided commercial NMR instruments ranging from a proton resonance frequency of $30 \mathrm{MHz}$ in 1952 to $100 \mathrm{MHz}$ in 1962. "The most successful Varian instruments, such as the HR30 (1952), HR40 (1955), HR60 (1958), and HR100 (1959), were all high resolution solutionstate spectrometers that were based on continuous-wave (cw) sweep methods and on electromagnets." [9] For routine chemical analyses at that time, the AR60 (60 MHz) was the workhorse, providing sufficient data quality and best value; as well as flexibility. In fact the famous imaging experiment designed by Lauterbur [11] was performed on such a system.

Despite the increases in flux density or field strength (and, thus, resonance frequency), overall sensitivity remained low due to the very slow $\mathrm{cw}$ measurement technique used at the time. Thus, stability, which was critically related to the stability of the electrical power supply, was a critical issue (Figures 1, 2, bottom left).

Although the technique started maturing, and chemical shifts were experimentally discovered and (partially) theoretically understood, chemists were reluctant to move from already established analytical tools, based on optical spectroscopy (UV/Vis, IR) and X-ray absorption and diffraction methods, to NMR $[9,12]$.

Besides improving sensitivity and reducing measurement time, the increased flux density $B_{0}$ additionally increases spectral dispersion. Provided sufficient field stability during long experimental runs, more and more fine details in NMR spectra could be resolved with the advent of shim tools for creating homogeneous magnetic fields, enabling sub-Hertz spectral resolution.

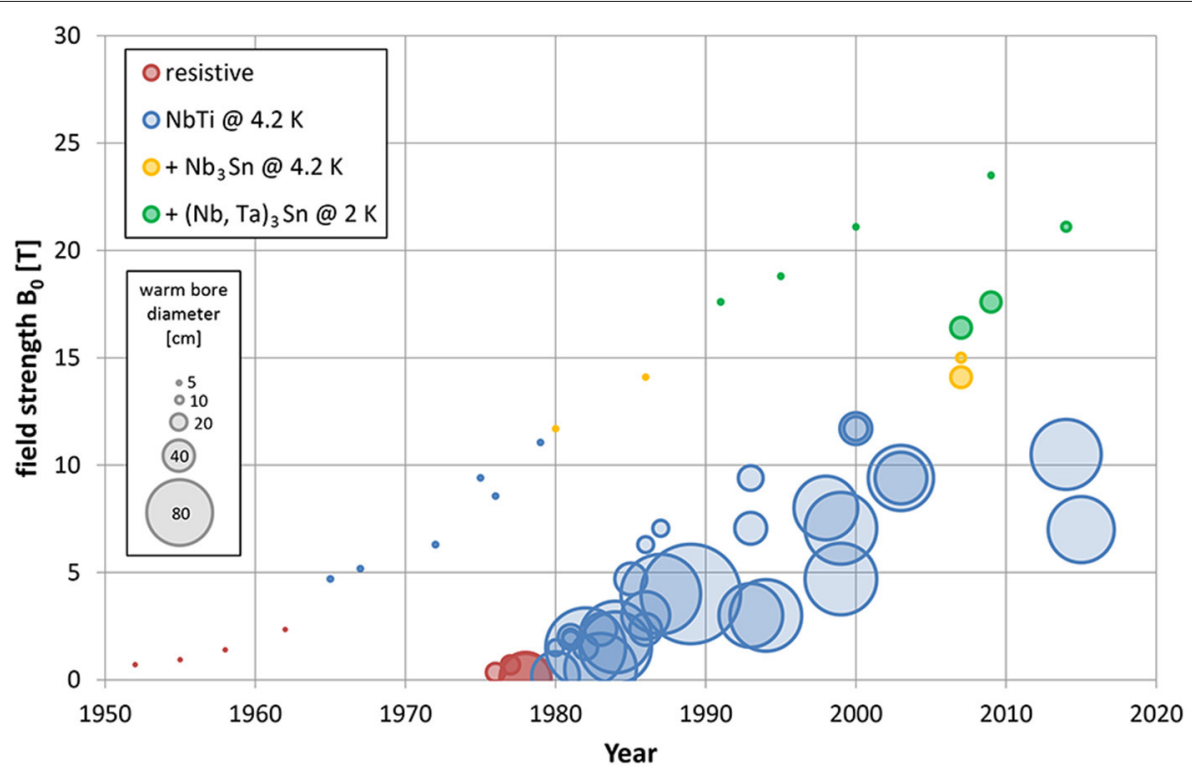

FIGURE 1 | Increase in field strength (and bore diameter) of commercially available NMR systems for analytical (points, left), biomedical and preclinical (small circles, middle), and human MRI and MRS (big circles, right). Please note the rather similar slopes of the analytical NMR and preclinical MR development, which are delayed in time by $\sim 15$ years. Both preclinical and human MR magnets started to evolve with the availability of reliable superconductor technology around the year 1980 . The slope for human magnet development is less steep, likely due to costs (size of the magnet) and legal constraints (slowly increasing upper legal limits for field strength in vivo). References for all data points are given in the Supplementary Materials. 


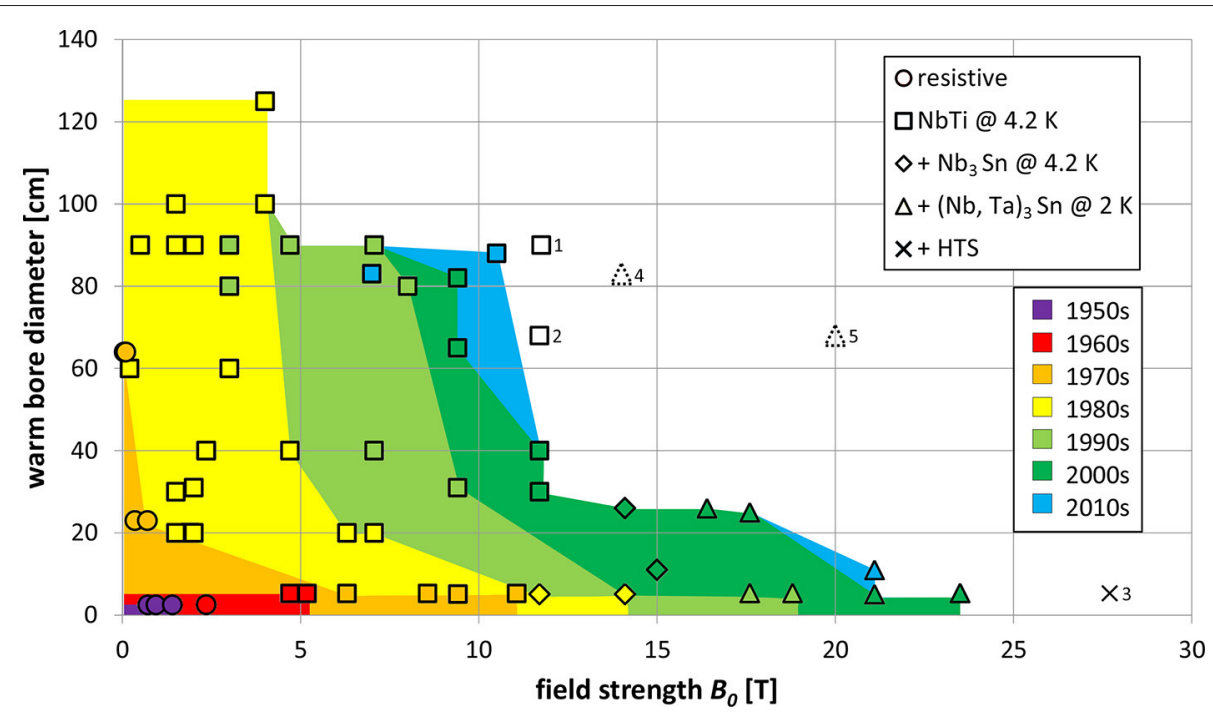

FIGURE 2 | Dependence of magnetic flux density (T) and bore size (cm) with color coding for the decade when the respective system was introduced. The shapes of the symbols represent the materials used for the magnet, as indicated in the legend. Magnets that have been successfully deployed in the field are shown with colored symbols. Symbols without color represent systems that have been installed, but are not yet fully functional (solid lines) or design studies (dotted lines). Details for these planned systems: (1) 11.75 T whole-body system CEA-Iseult, France, (2) 11.7 T head system, NIH, USA, (3) 28.2 T vertical bore system Garching, Germany, (4) Design study for $14 \mathrm{~T}$ whole-body system Heidelberg, Germany, (5) Design study for $20 \mathrm{~T}$ head system. Data and references for all data points are given in the Supplementary Materials. Fundamental limits due to the material are easily noticeable: in the lower left corner (i.e., low field strengths and small magnet bores) resistive magnets (copper wire) are clustered, with the superconducting magnets above (i.e., larger bores) and to the right (higher fields). Starting from $\sim 11$ to $12 \mathrm{~T}$, $\mathrm{Nb}{ }_{3} \mathrm{Sn}$ is used in addition to $\mathrm{Nb}$-Ti; from $\sim 15 \mathrm{~T}$, $(\mathrm{Nb}, \mathrm{Ta})_{3} \mathrm{Sn}$ is added. For the $28.2 \mathrm{~T}$ system, high-temperature superconductor is added.

Applications of in vivo systems started emerging, too. Already in 1965, proton NMR relaxation times of living frog muscle were published [13], and in 1968 the first whole-body spectrum of a rat was taken [14]. In the 1960s and 1970s a very large amount of work was published on relaxation, diffusion, and chemical exchange of water in cells and tissues of all sorts.

The highest field strength obtained with air cooled resistive electromagnets suitable for NMR, i.e., with an open gap of $2.5 \mathrm{~cm}$, was first commercially achievable in 1962. In parallel, already starting in 1955, the first operational superconducting (sc) magnet based on $\mathrm{Nb}$ wire and operating at $0.7 \mathrm{~T}$ [15] was developed.

It was discovered at this early stage, that the critical current in a magnetic field could be increased by cold working of the wire (creating flux pins) and reduced by annealing. Obviously, this changes the critical current $\mathrm{I}_{\mathrm{c}}$ and the upper critical field $\mathrm{H}_{2 \mathrm{c}}$.

Several years later favorable sc properties of $\mathrm{Nb}$ - $\mathrm{Ti}$ alloys, i.e., high critical magnetic fields and high critical current densities, were discovered and paved the way for commercial use in high field magnets [16]. It took some more time to produce truly reliable superconducting wires based on $\mathrm{Nb}$-Ti multifilaments embedded in a copper matrix, which could then be commercially used for large scale magnet production [7, 17]. The main reason for the long delay was flux jumping at increasing field strength, which strongly reduced the critical current and, thus, the achievable magnetic field strength [18]. Development was initially driven by requests from high energy physics, e.g., for particle accelerators, the production of superconducting magnets only became commercially viable around 1980 through the advent of large whole-body MRI magnets which by now is still, commercially speaking, the by far dominant application in terms of world sales of superconducting systems.

Bruker Spectrospin led by G. Laukien and T. Keller, and based on Trueb-Taeuber's expertise in high resolution NMR (supported by H. H. Guenthard and H. Primas from the University of Zurich), started later, however, turned out to be more innovative and flexible. In 1967 they built the first fully transistorized NMR spectrometer (HFX90) with three independent RF channels, for data acquisition, decoupling and spin-lock, allowing novel experiments and strongly simplifying routine experiments. In 1969, Bruker Inc. presented the first pulsed FT-NMR spectrometer based on Richard Ernst's Fourier transform technique [9, 19], which for the first time allowed the acquisition of excellent ${ }^{13} \mathrm{C}$-spectra. Shortly thereafter, they presented the first high field NMR spectrometer built around a superconducting magnet (WH270), kicking-off the "arms race" for ever higher and higher field strengths in analytical NMR (Figure 1, left).

This made the technique more and more attractive for chemists, who took advantage of the increased sensitivity, which allowed the observation of low $\gamma$ nuclei and increased spectral resolution.

On the other hand, technically this also made in vivo MRS and MRI possible $[20,21]$ - see also phase B. Direct in vivo ${ }^{31} \mathrm{P}$ NMR spectroscopy in living cells was first performed in Oxford from 1974 on, in the group of Rex E. Richards and George K. Radda.

On 2 September 1971, Paul C. Lauterbur, a professor of chemistry at the State University of New York at Stony Brook, 
patented the idea of applying magnetic field gradients in all three dimensions to create NMR images [22]. Ideas spread quickly and first NMR images were already produced in the early 1970s [11], and human fingers and wrist were originally imaged in resistive, vertical NMR magnets operating at 0.35 $\mathrm{T}$ [23] and $0.7 \mathrm{~T}$ [24]. The first in-vivo whole-body scan was performed on Peter Mansfield's abdomen in 1978, still using resistive electromagnets, at ultra-low field strength$0.094 \mathrm{~T}[25,26]$. Early commercial MRI scanners prescribed for clinical diagnosis, e.g., Bruker's Tomikon, were also still based on resistive electromagnets with iron yokes, operating between $0.1 \mathrm{~T}$ and $0.28 \mathrm{~T}$. Due to field stability limitations, counterbalanced by an iron-yoke and dedicated electronics, only $\mathrm{T}_{2}$-weighted-imaging was feasible at sufficient quality and speed. The first large superconducting magnet was designed and built by Oxford Instruments (OI) around 1980, and the first prototype MRI system was installed at the Hammersmith Hospital, London (UK).

This phase has been highlighted by the two Nobel prizes in Chemistry for Richard R. Ernst (1991) and Kurt Wuethrich (2002), both from the ETH Zurich, and Paul C. Lauterbur and Peter Mansfield in Medicine (2003) but the full success in terms of applications only came during phase C-the Golden Age of NMR.

The upper limit for fully resistive magnets that have been reached so far are currently installed in Hefei, China (38.52 T in $32 \mathrm{~mm}$ ), Nijmegen, The Netherlands (37.53 $\mathrm{T}$ in $32 \mathrm{~mm}$ ), Tallahassee, USA, and Grenoble, Switzerland (36 T in $32 \mathrm{~mm}$ and $34 \mathrm{~mm}$, respectively). However, they require electrical power typically in the range $24-30 \mathrm{MW}$. All resistive magnets except those from Grenoble are of Florida Bitter type.

\section{PERMANENT MAGNETS, THE LOW COST ALTERNATIVE}

In parallel, low-resolution NMR systems based on permanent magnets (typically $\leq 0.5 \mathrm{~T}$ or $20 \mathrm{MHz}$, using various rare earth materials) have been applied to measure relaxation times in fluids, cells and excised animal or human tissue. These systems provide a cost-effective and simple alternative to high-resolution systems required in analytical chemistry. This is mainly due to low electric power requirements, low stray fields, and, thus, low production and siting costs (even bench top systems are available).

Erik Odeblad, a gynecologist, after his stay at Stanford at about the time of Bloch's discovery, went back to Stockholm and, together with G. Lindstroem, built his own low-resolution NMR spectrometer. Widely unnoticed by the scientific NMR community they found out, and already published in 1955 [27], that different tissues had distinct relaxation times, most likely due to different water content but also due to different compartmentalization and interections with lipids-a phenomenon that explains tissue contrast in MR imaging. Odeblad continued working on human fluids and tissues throughout the following decades and a large number of scientific papers on NMR relaxation in human tissues and secretions of mucous membranes followed until 1968 [22].
In 1975 Bruker presented the first commercial $20 \mathrm{MHz}$ lowresolution spectrometer for industrial applications, like food quality control, also used to measure soft tissues and body fluids. A large number of studies between the 1960s and 1990s have been published by several research groups using low resolution ${ }^{1} \mathrm{H}$-relaxometry to study relaxation time differences in different animal and human tissue ex vivo, at different field strength $[28,29]$ and under different storage conditions [30, 31]. Lowresolution, low-cost NMR is still in use today (e.g., Bruker's Minispec product line), particularly for quality control in the food industry and for well logging [32].

For historical purpose we should mention that for a certain period of time scaled-up permanent magnets were used for human MRI (e.g., FONAR Corp. 1980), however, they were severely limited by their weight (up to $300 \mathrm{t}$ ), cost and low field homogeneity. In addition, FONAR announced the first vertical MRI in 1996 and upright human MRI in 1999, enabling dynamic weight-bearing multi-position MRI at $0.6 \mathrm{~T}$ [33], potentially useful for claustrophobic patients.

Today, cost effective and custom made, small-size permanent magnets $(0.3 \mathrm{~T}-0.4 \mathrm{~T})$ can already be home made in a $3 \mathrm{D}$-printer in all kinds of shapes and field profiles using polymer-bonded magnetic material [34].

\section{SUPERCONDUCTING ELECTROMAGNETS, THE GOLDEN AGE OF NMR}

All superconducting magnets developed so far for analytical $\mathrm{NMR}$, and preclinical or human MRI and MRS, employ Nb$\mathrm{Ti}$ or $\mathrm{Nb}_{3} \mathrm{Sn}$ as the superconducting material and copper as stabilizer and enforcement material. This works up to a certain field strength and bore diameter as the hoop stress $F / S=a J B$ $R$ (with $a$ a geometrical factor, $J$ the current density, $B$ the flux density proportional to $J, R$ the radius) increases quadratically with the current density $J$. This sets an upper limit for the use of $\mathrm{Nb}-\mathrm{Ti} / \mathrm{Nb}_{3} \mathrm{Sn}$ and copper $[4,6]$. Using $\mathrm{Nb}_{3} \mathrm{Sn}$ is more expensive, because the material is rather brittle, and e.g., for field strengths higher than $12 \mathrm{~T}$ for a large bore magnet would therefore require high temperature superconductors (HTS) and steel enforcement as well [6].

The stored energy in the magnet coil $E=L \times I^{2} / 2$ (with $L$ being the self-inductance of the coil and $I$ the current) is plotted against the magnetic flux $F$ in Figure 3, empirically showing a quadratic dependence.

\section{Analytical NMR}

The reason for the success of NMR in chemistry is that it does not require extensive sample preparation (e.g., crystallization), studies molecules in solution in their natural environment and can identify topological relationships between nuclei through their scalar coupling and dipolar interactions. Moving from organic chemistry to structural biology allows studies of the structure, dynamics and function of larger and more complex biological macromolecules [35]. 


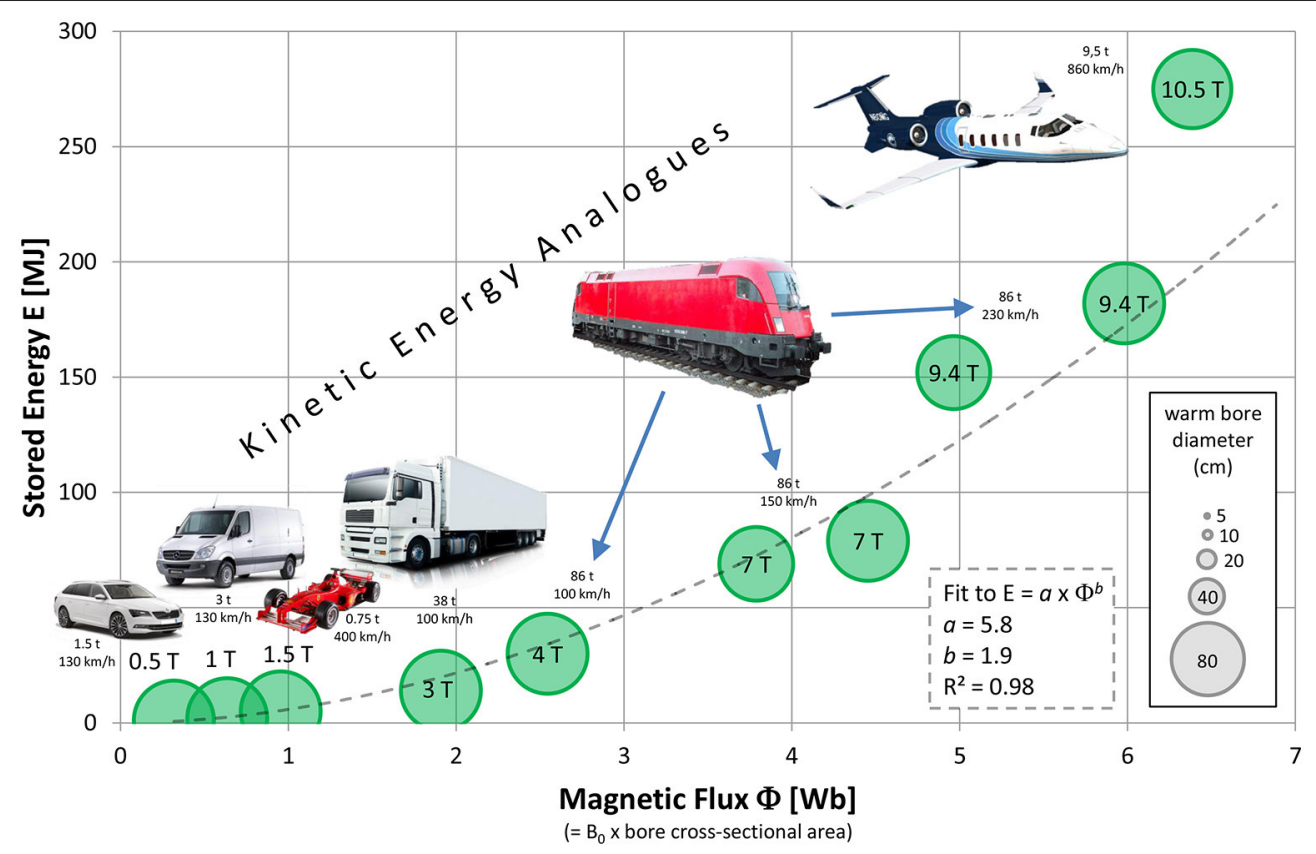

FIGURE 3 | Amount of energy stored in the magnet vs. magnetic flux (calculated from the warm bore diameter), showing an empirical trend of quadratic increase (dotted line). For illustration, everyday analogs in the form of vehicles with kinetic energy similar to the stored energies are depicted with their respective masses and velocities. Data and references for all data points are given in the Supplementary Materials. Please note that more precisely, the diameter of the magnet coils instead of the warm bore diameter should have been used for the calculation of magnetic flux; unfortunately this data could not be retrieved. However, when adding a constant offset in the range of $5-15 \mathrm{~cm}$ to the bore diameters for all data points, the fit still yields the quadratic dependence and only differs in its steepness a.

However, the extension to higher molecular mass also requires higher magnetic fields. In addition, more complex multidimensional experiments are employed and concentrations of interesting molecule are low $(<1 \mathrm{mM})$. Furthermore, higher throughput in commercial applications requires shorter experiment times. Altogether, this requires higher and higher field strengths. Thus, the driving force in NMR has been the scientific quest to study more complex molecules and interactions leading to a field increase over the last 40 or so years of about $20 \mathrm{MHz}$ (or $0.5 \mathrm{~T}$ ) per year on average (Figure 1, left). As spectral resolution increases linearly with $B_{0}$ and the sensitivity in small, non-conducting samples with $B_{0}{ }^{7 / 4}$, the acquisition time can be reduced by almost $1 / B_{0}{ }^{3}$. Thus, nothing other than economical aspects will slow down the quest for ever higher magnetic fields in NMR. Figure 1 (left) visualizes this success story of the past 65 years, moving from 30 to $100 \mathrm{MHz}$ using resistive, air-cooled electromagnets, to $\mathrm{Nb}-\mathrm{Ti}$ single- and multifilament sc magnets up to $400 \mathrm{MHz}$ $(9.4 \mathrm{~T})$ and using combined $\mathrm{Nb}-\mathrm{Ti}$ and $\mathrm{Nb}_{3} \mathrm{Sn}$ multifilament wires up to $600 \mathrm{MHz}(14.1 \mathrm{~T})$ at boiling $\mathrm{He}$ temperature $(4.2 \mathrm{~K})$. Above $15 \mathrm{~T}$ sc-wires are manufactured from $(\mathrm{Nb}$, $\mathrm{Ta})_{3} \mathrm{Sn}, \mathrm{Nb}_{3} \mathrm{Sn}$ and $\mathrm{Nb}-\mathrm{Ti}$, and to further increase the current density wires are now square shaped and can operate up to $800 \mathrm{MHz}(18.8 \mathrm{~T})$ at $4.2 \mathrm{~K}$ and up to $1,000 \mathrm{MHz}(23.5 \mathrm{~T})$, if cooled to $2 \mathrm{~K}$. All magnets in NMR are vertical, narrow $(50-54 \mathrm{~mm})$ or wide $(89-110 \mathrm{~mm})$ bore. To improve NMR safety and siting requirements, actively shielded high-field NMR magnets have been developed starting in 1995. As a downside, magnet costs and weight increases due to a $30 \%$ loss in $B_{0}$ and increased amount of sc wire for the active shielding.

The strongest commercially available magnet currently used in the field operates at $23.5 \mathrm{~T}$, weighs 12 tons and is $4.5 \mathrm{~m}$ tall. It was first installed at the European Center for High Field NMR (CRNM) in Lyon, France, in 2009 at the cost of $€ 11.7$ million. Subsequently, a new generation $1 \mathrm{GHz}$ system, this time including active shielding and Helium refrigeration and recovery was installed at the University of Bayreuth, Germany, between 2015/2016. At $1 \mathrm{GHz}$ new horizons open in structural biology, metabolomics and material science. Although the increase in field strength is only about $11 \%$ over previously available $900 \mathrm{MHz}$ spectrometers, there is a significant increase in speed and sensitivity for low concentration samples [36].

Naturally, not every university or research center will be able to install such a system, the CRNM-funded also via the EU-is a resource for the whole NMR research community. Along this avenue, several universities world-wide already ordered a next generation $1.2 \mathrm{GHz}$ spectrometer from Bruker; expected delivery time is $2017 / 18$. Technically, the $1.2 \mathrm{GHz}$ and higher systems depend on further progress in HTS conductor developments and HTS-based NMR magnet technology, including superconducting joints, switches and cables. Application wise, such systems will open up a broad range of interdisciplinary research applications in structural biology, catalysis, sustainable energy development as well as biomedical applications, to name just a few $[35,37]$. 


\section{Biomedical and Preclinical MRI and MRS Research}

After early attempts on whole animals [14], numerous studies of live, intact animals took place in the 1970s to investigate anatomy, biochemistry, and physiology in vivo [38-41], also using perfused organs (e.g., [42-44]). In 1979, Britton Chance at University of Pennsylvania (PA, USA), contacted OI (UK) to design and build the first horizontal $1.5 \mathrm{~T} / 20 \mathrm{~cm}$ magnet for metabolic research. This MRS system had no shimming capabilities and no gradients, thus could be used only for ${ }^{31} \mathrm{P}$ MRS with small local $\mathrm{Tx} / \mathrm{Rx}$ (transmit/receive)-coils. It was used to study human arm muscle as well as small animals. A similar magnet was delivered to Harvard University (MA, USA) in 1980 and, subsequently, the first magnet, which was a commercial product $(1.5 \mathrm{~T} / 30 \mathrm{~cm})$ was delivered to $\mathrm{G}$. K. Radda at Oxford University by OI [38]. Magnetic field strength for preclinical MRI and MRS scanners always followed in between the development for analytical NMR and human scanners (Figure 1, middle), just varying with bore diameter (i.e., about $10-20 \mathrm{~cm}$ for mice and rats and up to $40 \mathrm{~cm}$ for larger animals). Nowadays, highfield, small bore (horizontal) MRI and MRS scanners have been installed in most biomedical research institutions and research driven medical universities. Although various types of animals are being studied, the main targets still are rats and mice due to availability, cost, and the possibility to create genetically modified knock-out strains. As particularly large numbers of specifically modified mice are available today, noninvasive imaging is very attractive for mice phenotyping. Therefore, dedicated mouse imaging centers have been established and are frequently used to study genetic defects and to develop novel pharmaceuticals [45]. In parallel, substantial progress in the diversification and innovation of MR methods and increased sensitivity due to improving hardware and, particularly ultra-high-field magnets, provided a strong impetus to multi-parametric MRI and MRS of (small) laboratory animals $[45,46]$.

To further enhance sensitivity, without the need for increased magnetic field strength, cryo-cooled (20-25K) RF coils have been developed [47]. This drastically reduces the thermal noise and is a rather cost effective way to substantially improve sensitivity and still work at well established field strengths and frequencies between $7 \mathrm{~T}(300 \mathrm{MHz})$ and $11.7 \mathrm{~T}(500 \mathrm{MHz})$. However, at higher frequencies this approach becomes less effective because already for small coil (element) diameters the noise becomes sample-dominated. Although even stronger magnets are available for MRI of mice, i.e., up to $21.1 \mathrm{~T}$, both costs and requirement for installation and operation of such systems limit their widespread use. Furthermore, physiological effects may limit studies on awake, behaving animals at $14 \mathrm{~T}$ or higher [48]. Whether or not this may also affect functional and metabolic studies in anesthetized animals yet has to be shown.

\section{Clinical MRI and MR Research Using Whole-Body Superconductors}

First images of human finger and wrist were taken at Nottingham still using vertical bore, resistive magnets $(0.35 \mathrm{~T}$ and $0.7 \mathrm{~T}$, respectively) in 1977 [23, 24, 26]. Human whole-body MRI prototype scanners have been co-developed by OI and installed during the late 1970s, employing resistive electromagnets operating at $0.05 \mathrm{~T}$ in Aberdeen and $0.094 \mathrm{~T}$ at Nottingham $[20,21,25,26,49]$. Homogeneity over a sufficiently large volume as well as long-term field stability (temperature dependent) was critical though. The first MRI scanner installed at a private radiology unit was probably Bruker's Tomikon using resistive electromagnets at $0.1 \mathrm{~T}$ and up to $0.23 \mathrm{~T}$.

In parallel to proton $\mathrm{MR}$ imaging, metabolic research using ${ }^{31} \mathrm{P}$ MRS was performed mainly by research groups in the UK and USA. There the focus was on cerebral metabolism in newborns $[50,51]$ and adult muscle metabolism [52, 53]. Due to the limited sensitivity for low- $\gamma$ nuclei and high requirements on technical and biochemical expertise, however, this application was less successful in a clinical setting despite high expectations [54].

High-quality clinical MRI became commercially available only in the mid 1980s, after superconductors (using Nb-Ti filaments in a copper matrix) could be employed successfully for wholebody magnets. Already in 1985 the first 10 commercial "highfield" (=1.5 T) MRI systems have been installed, although the majority of the clinical MRI systems at that time operated at $<1$ $\mathrm{T}$ (in the early days of MRI there have been intense discussions about the optimum field strength, i.e., sensitivity/image SNR vs. specificity/tissue contrast). The total numbers installed increased steadily until 1992 where about 1250 units have been sold world-wide. In 1997 it became obvious that the low field systems are on a decline and $1.5 \mathrm{~T}$ became the "standard" clinical field strength. Due to the increased sensitivity, not only via $B_{0}$ but RF-coil design, contrast agents and fast imaging protocols, speed and contrast could be improved significantly. By 2003 about $65 \%$ of all MRI systems installed operated at $1.5 \mathrm{~T}$ (this very year already about 2,750 units have been sold). Research at $3 \mathrm{~T}$ started in the late $1980 \mathrm{~s}$ (3T/80 cm, Detroit), on passively shielded prototype systems with fast gradients and local transmit-receive coils. Today, MRI is widely used for noninvasive imaging of internal body structures, providing high soft tissues contrast, at field strengths up to $3 \mathrm{~T}$ for clinical routine and $7 \mathrm{~T}, 9.4 \mathrm{~T}$ and $10.5 \mathrm{~T}$ (a $11.7 \mathrm{~T}$ for head only MRI scanner was designed, however, at the time of writing this magnet was out of order due to magnet quench) for research only [55-63].

Supporting particularly the booming field of functional MRI including BOLD-based contrast, started in the early 1990s, $3 \mathrm{~T}$ systems with strong and fast gradient coils have been developed in parallel and the first "high end" routine MRI systems operating at that field strength became commercially available in 2000. Together with "parallel imaging," i.e., array coils and SENSE [64]/GRAPPA [65] techniques, this move turned out to be extremely successful and quickly, i.e., within 10 years, $20 \%$ of all MRI sales are 3 T. BOLD-based fmri, greatly benefitting from the increased $\mathrm{B}_{0}$ and faster/stronger gradients, was the driving force for developments and sales of $3 \mathrm{~T}$ systems. The following decade in clinical routine and research was characterized by a plateau in terms of newly installed systems (about 3,000 units p.a.), where $3 \mathrm{~T}$ systems started replacing the lower field units. Robust and strong/fast gradient 
coils and efficient phased-array RF-coils (requiring multi-channel receive electronics) helped to constantly improve (fast) imaging performance. Again, the higher sensitivity achievable could be used for speed and increasing specificity, now also via multiparametric imaging, e.g., combining structural and functional MRI, resulting in exam times still well tolerated by patients. For high resolution, localized MR spectroscopy of non-proton nuclei (e.g., ${ }^{31} \mathrm{P},{ }^{13} \mathrm{C}$ ), the sensitivity was still too low to incorporate such a protocol into clinical routine. By 2015 , about $60 \%$ of all clinical MRI volume sales were achieved for $1.5 \mathrm{~T}, 34 \%$ for $3 \mathrm{~T}$ systems (slowly replacing current $1.5 \mathrm{~T}$ scanners), and a rather stable $6 \%$ for low field scanners $(<0.5 \mathrm{~T})$. Although a few 4 $\mathrm{T}$ and $4.7 \mathrm{~T}$ prototype magnets have been installed since 1988 , stronger magnets have been operating at $7 \mathrm{~T}$ for UHF research only $[57,58,61,66,67]$. Thus, $7 \mathrm{~T}$ human whole body scanners are currently only being installed in selected high end (clinical) research units (with about 70 systems installed so far). Currently, FDA approval has been obtained only for Siemens' $7 \mathrm{~T}$ Terra system, centered around an active shielded compact magnet and standard operating software/console.

A first $8 \mathrm{~T}$ Magnex prototype UHF magnet was installed at Ohio State University (1998) and has been operating for some time [59]

Shortly before he died in January of 1988, physicist I.I. Rabi was scanned in an MRI machine. When looking at his MR image he said "I never thought my work would come to this." (adopted from [68]).

This phase was essential for the Nobel Prize in Medicine or Physiology, awarded to Paul C. Lauterbur (Illinois, USA) and Sir Peter Mansfield (Nottingham, UK) in 2003, although their relevant scientific work started much earlier using resistive electromagnets but strongly stimulated the rapid development of human MRI-using whole-body, high-field superconducting magnets-and a wide range of still vivid methodological research and, subsequently, clinical applications.

\section{HYBRID MAGNETS, BACK TO THE FUTURE}

In order to be able to further increase the (persistent) static (dc) magnetic field, i.e., sensitivity in NMR, hybrid magnet concepts have been pursued for some time $[5,6]$. Combining superconductors and resistive electromagnets, hybrid magnets allowed engineers to create a dc magnetic field of about 45 $\mathrm{T}$, where the outer superconducting coil consists of three grades of $\mathrm{Nb}_{3} \mathrm{Sn} \mathrm{CICC}$ and the resistive coil insert consists of four nested Florida-Bitter coils [6]. However, the free inner bore is only $54 \mathrm{~mm}$ (unshimmed $50 \mathrm{ppm}$ ), intended to provide $1 \mathrm{ppm}$ homogeneity and stability over a $1 \mathrm{~cm}$ diameter spherical volume. Nevertheless, in depth studies have started to design a $60 \mathrm{~T}$ dc magnet at the National High Magnetic Field Laboratory in Florida, using also HTS cables [6]. In addition to known problems of field stability and homogeneity, the energy stored and mechanical forces will dramatically increase (Figure 3), requiring novel concepts like steel enforcement and superconducting cables. Last but not least, extremely high costs currently prevent commercialization of these designs.

\section{Innovation and Commercialization}

The NMR/MRI market has always been dominated by a limited number of companies. Very early on Varian Inc., an innovation leader, developed a dominant position in the NMR market. In the late 1960s a young, entrepreneurial European company (Bruker Inc.) gained on the change in technology, i.e., from resistive to superconducting magnets and from CW to FT experiments, and built a strong position in analytical NMR and, later, biomedical and preclinical MRS and MRI. Nevertheless, Varian, taken over by Agilent in 2008, still was a strong player in the field until 2013. Obviously, a series of management decisions (e.g., to stop producing UHF NMR magnets beyond $200 \mathrm{MHz}$ ), and relying on third party magnet manufacturers instead, as well as an overgrown bureaucracy led to an unfavorable end of a once famous company [69].

Intermagnetics General Corporation (IGC), founded 1971 as a spin-off of General Electric (GE), was an early provider of (superconducting) wire and magnets. In 1974 IGC became independent of GE and had its initial public offering in 1981. In the early 1980s, for most clinical MRI systems (e.g., Picker, Diasonics, Technicare as well as GE, Siemens, and Philips) superconducting magnets were provided either by IGC or OI and later Oxford Magnet Technology (OMT), a subsidary of OI (1989 a joint venture between OI/OMT and Siemens was signed and OMT fully taken over by Siemens in 2003 and renamed SMT). Philips Medical Systems ordered their magnets mostly from IGC and finally acquired IGC in 2006. General Electric Medical Systems (GEMS) first ordered magnets also from IGC and later developed their own magnets in a facility in Florence, SC (South Carolina). Magnex Scientific Ltd. (MAGNEX) was founded in 1982 and delivered $0.5 \mathrm{~T}$ and $1.5 \mathrm{~T}$ magnets for Elscint starting 1983. In 1988 MAGNEX developed the first shielded $3 \mathrm{~T}$ MRI magnet $(80 \mathrm{~cm} \mathrm{WB})$ for the Henry Ford Hospital (Detroit, USA). After a strategic partnership of MAGNEX and GEMS in 1996 the clinical business of MAGNEX was sold to GEMS in 2000 (for the only purpose to have $3 \mathrm{~T}$ technology available). Eventually, all clinical MRI manufacturers, including also Hitachi and Toshiba, had their own magnet production secured in order to be able to control quality and costs. In 1998 MAGNEX developed the first $8 \mathrm{~T}$ whole-body research magnet for Ohio State University and in 1999 the first $7 \mathrm{~T}$ clinical research magnet for University of Minnesota. GEMS, however, decided very early on to stop their activities in UHF magnets manufacturing for humans, which was based on MAGNEX technology, they rather invested in the application of hyperpolarized gases to increase much needed sensitivity. The research division of MAGNEX supplied MRS products and was transferred to Varian Inc. starting 2002, and Varian Inc. acquired Magnex Scientific Ltd. in 2004. Tesla Inc. was founded in 2014 in the UK after Agilent/Varian announced closure of the production of specialty UHF magnets for human MRI and MRS research. The near future will show whether magnet concepts developed for accelerators in high energy physics and for fusion reactors such as ITER, i.e., 
high field, low He use, may be transferred to perform in UHF human MRI.

\section{Safety Issues Due to Static Magnetic Fields}

Finally, we should not miss to summarize our current knowledge of safety issues concerning static magnetic fields and safety precautions in case of a magnet quench [70]. Empirically, most people experience some physiological sensations when moving their head in/into a $3 \mathrm{~T}$ magnet or even more so in a stronger magnetic field, like a certain metallic taste, dizziness, or short flashes of light (i.e., phosphenes) even when eyes are closed. When they stop moving or get out of the magnet these sensations disappear. As early as 1986 the Oxford group led by Radda (at $1.6 \mathrm{~T}$ ) and in 1999 the Ohio group led by Robitaille performed studies on swine and humans in order to elucidate potential side effects of strong static magnetic fields on physiological or cognitive functions. The latter study of 10 healthy human subjects provided no evidence of measurable changes in body temperature, heart rate, respiratory rate, systolic pressure, or diastolic blood pressure after $1 \mathrm{~h}$ of exposure at $8 \mathrm{~T}$ [71]. Furthermore, no cognitive changes were noticeable. However, significant ECG changes have been noted which were related both to the position of the subject in the magnet and to the strength of the static magnetic field. Thus, the common ECG tracing was no longer diagnostically useful when performed at 8 T. Nevertheless, all (healthy) subjects showed normal ECG readings before and after the exposure to the $8 \mathrm{~T}$ static magnetic field. In addition, cardiac function was examined in some detail in an anesthetized swine. No significant changes in "body temperature, heart rate, left ventricular pressure, left ventricular end diastolic pressure, time rate of change of left ventricular pressure, myocardial stiffness index, cardiac output, systolic volume, troponin, and potassium levels could be detected following $3 \mathrm{~h}$ of exposure to a field strength of 8.0 tesla. It is concluded that no short term cardiac or cognitive effects are observed following significant exposure to a magnetic field of up to 8.0 tesla." Following up on this and due to the increase in UHF magnets installed world-wide a special issue on Effects of static magnetic fields relevant to human health appeared in the journal Progress in Biophysics and Molecular Biology in 2005 (Volume 87). Again, it was concluded that "no permanent adverse effect on human subjects when exposed to static magnetic fields in strengths of up to $8 \mathrm{~T}$ could be detected. Also, there is no evidence of any clinically relevant alteration in human neuro-cognitive function related to static magnetic field exposure. Results suggest that the cognitive-motor (eye-hand coordination) and the sensory (nearvisual contrast sensitivity) function are negatively influenced by exposure to magnetic fields as low as $700 \mathrm{mT}$. Although these effects are undesirable in interventional MRI procedures (and potentially affect functional MRI studies), it is not clear how these transient effects relate to actual performance in a clinical setting. The risks related to the interaction of a static magnetic field and magnetic or electrical hardware are much greater than the apparent biological interaction risks to human subjects alone." [72].

However, an epidemiological review by Feychting [73] within the same journal/issue concludes that "the available evidence from epidemiological studies is not sufficient to draw any conclusions about potential health effects of static magnetic field exposure." Nevertheless, counting on numerous staff working at various field strength over decades, it seems unlikely that typical exposure to static magnetic fields of a few hours per day in the fringe field (i.e., below about 1 $\mathrm{T}$ at a clinical $3 \mathrm{~T}$ MRI system or below $2 \mathrm{~T}$ at a $7 \mathrm{~T}$ UHF MR system) will cause severe long term health problems (Personal Note: all authors had been exposed to strong static magnetic fields for decades without any adverse effects so far besides the dizziness effects while entering the magnet bore).

On the other hand, implanted ferromagnetic devices within patients (e.g., life supporting pace makers, passive hip or knee implants are less affected) and physical interactions between external magnetic material (like coins, working tools or medical equipment not checked for UHF compatibility) pose substantial hazards and represent a severe source of risk. Therefore, it seems imperative that vigilance be maintained at ever higher field strengths to ensure that the high degree of patient and staff safety so far associated with clinical MRI and high field research is maintained [74]. Especially, due to the shorter wavelength of the radio frequency fields at higher static field conductive implants and other metallic objects must be treated with caution, e.g., by accurate electromagnetic simulation, or, in doubt, excluded from MR examinations to minimize the risk of burn injuries. This becomes even more complicated by parallel transmission technology.

Based on empirical evidence, revealing uncomfortable physiological sensations in some of the volunteer studied in UHF MRI, several systematic studies have been performed [75-77] and the basic mechanisms of vertigo in high magnetic fields described [76, 78]. Despite the low magnetic susceptibility of human tissues and the lack of any substantial amount of ferromagnetic material typically occurring in healthy subjects, experimental evidence supports the hypothesis that magnetic-field related vertigo results from both magnetic susceptibility differences between vestibular organs and surrounding fluid, and induced currents acting on the vestibular hair cells. Both mechanisms are consistent with theoretical predictions [76]. This may cause a limit for routine clinical examinations at $7 \mathrm{~T}$ or higher $[48,79]$, as up to $12 \%$ of healthy subjects experience such a brain exam as unpleasant. However, it should also be noted that subjective perception of metallic taste, vertigo and nausea may vary widely and that there exists a drug to prevent or reduce vertigo and nausea [80].

\section{Future Directions in Human MRI and MRS Analytical NMR}

It seems obvious that the magnet development in analytical NMR is approaching technical limits. First, frequencies of $1,200 \mathrm{MHz}$ and above cause technical problems in coil/probe manufacturing. Second, RF-penetration limits further frequency increase (unless sample size/volume is reduced, which again reduces sensitivity), and, third, 
economics. Most routine applications in NMR work efficiently and cost effectively at $400-600 \mathrm{MHz}$, with special research applications at $800-1,200 \mathrm{MHz}$. Therefore, strategies to improve SNR even at lower field are requested and may be preferred as cost saving alternatives for routine analytical NMR [37].

\section{Preclinical MRI and MRS}

In preclinical MRI and MRS most labs work at field strength between $7 \mathrm{~T}$ (where the clear magnet bore allows application to rats), actually the bulk of preclinical research is performed at this field, and 11.7 $\mathrm{T}$ (at which available magnet bore diameter limits application to mice). To further increase sensitivity, either cryo-cooled probeheads and coils can be used for another $\sim>2$-fold gain in sensitivity, which is much more cost effective than doubling the field strength [47]. Furthermore, physiological effects experienced by awake laboratory animals might limit the upper static field to about $14 \mathrm{~T}$ [48] and the same might apply to human subjects as well. In this regime shear forces acting in the vestibular system and between gray and white matter might be an issue [78], as well as cognitive function (e.g., in fMRI experiments). On the other hand, anesthetized animals will not be affected to the same extend.

\section{Ultra-High Field Human MRI and MRS}

Concerning ultra-high field human MRI and MRS we need to further increase sensitivity and/or speed to enable full multiparametric diagnosis within still comfortable total measurement time for patients. Also, we may trade (e.g., in $\mathrm{fMRI} /$ parenchyma) sensitivity for specificity (resolution vs. partial volume) if SNR is sufficient. Susceptibility based contrast in (functional) MRI benefits particularly from higher field strength, thus methods increasing specificity like spin-echo based fMRI vs. gradient-echo based fMRI may be more viable. On the other hand, we must not risk any short or long term hazard to the patient and personnel (for more details see also above), or increase discomfort due to (reversible) physiological sensations and, thus, damage the reputation and non-invasive status of the MR methods altogether [70, 74, 76, 78, 81]. In addition, a recent paper describes that one third of the patient scanned at $3 \mathrm{~T}$ and $7 \mathrm{~T}$ noticed stronger vertigo and nausea at the higher field strength [79].

\section{Routine Clinical MRI and MRS}

In routine clinical MRI and MRS, after about 35 years, the race for higher field strength would seem to be settled by the market already:

At the time being, about $33 \%$ of MRI sales volume per annum are $3 \mathrm{~T}$, while $60 \%$ still are $1.5 \mathrm{~T}$ and $6 \%$ are below $1.5 \mathrm{~T}$. Thus, $1.5 \mathrm{~T}$ is the bread and butter field strength, covering the majority of clinical applications, and is providing the best possible compromise between sensitivity, speed, and imaging specificity (including prescription of contrast agents), and cost. This, of course, includes form and organ fitted phased-array RF-coils (enabling parallel imaging), as well as optimized MR-sequences and image reconstruction. Gradient strength achievable $(45 \mathrm{mT} / \mathrm{m}$ and $200 \mathrm{mT} / \mathrm{m} / \mathrm{ms}$ slew rate), without disturbing Peripheral Nerve Stimulation (PNS) or else seems optimal also at $1.5 \mathrm{~T}$.

$3 \mathrm{~T}$ MRIs are high-end clinical systems, particularly valuable in Neuroradiology, muscular-skeletal MRI, and clinical MRS [82].

For very specific clinical applications and research in high resolution, metabolic imaging like CEST and multinuclear, localized spectroscopy, $7 \mathrm{~T}$ is extremely useful [57, 58, 63, 66]. However, $7 \mathrm{~T}$ systems are more expensive and demanding in terms of siting and personnel required. Although imaging with $\mathrm{CP}$ transmit coils is sufficiently good for head and joints (in particular knee), parallel transmit excitation ( $\mathrm{pTx}$ ) is required to manage other organs. SAR limits are independent of field strength, but their supervision is drastically more complicated for multiple RF transmit channels with independent time-varying amplitudes and phases, especially due to a stronger dependence on the individual patient anatomy. Solution strategies have been proposed, but have not been implemented broadly in the field yet.

On the receive side, starting from $1.5 \mathrm{~T}$ and higher, the use of phased array receive coils has been proven advantageous. Their main benefits are the acceleration of the acquisition, shortening of TE, and/or better SNR in more superficial regions closer to the coil elements. Phased array coils are used in almost all current clinical MRI applications and are also benefitting hetero-nuclear MRS and MRSI.

Gradients, for signal localization, on the other hand are more or less independent of the field strength used, although it is also advantageous to increase gradient performance when increasing the field strength. Figure 4A shows the increase in peak gradient strength $(\mathrm{mT} / \mathrm{m})$ and slew rate $(\mathrm{SR} ; \mathrm{T} / \mathrm{m} / \mathrm{s})$ of human MRI scanners over time. Clinical MRI scanners at $1.5 \mathrm{~T}$ nowadays use up to $45 \mathrm{mT} / \mathrm{m}$ at a slew rate (SR) of $200 \mathrm{~T} / \mathrm{s} / \mathrm{m}$. At $3 \mathrm{~T}$ the high-end performance is now $80 \mathrm{mT} / \mathrm{m}$ but SR is still at $200 \mathrm{~T} / \mathrm{m} / \mathrm{s}$ due to PNS. While $7 \mathrm{~T}$ gradients are now in the range of $70-80 \mathrm{mT} / \mathrm{m}$ it is often desirable to go higher, but some adverse effects need to be considered, such as acoustic noise and mechanical vibrations. As it is known, the driving force behind mechanical vibration and acoustic noise is the Lorentz force, which is proportional to the field strength $B_{0}$ and the gradient strength, too. This is causing some limitations for the peak gradient strength. Slew rate on the other hand is limited by PNS, which are entirely independent of the magnetic field strength. The current limit for whole body gradients thus is SR $200 \mathrm{~T} / \mathrm{m} / \mathrm{s}$. To get beyond this limit, one needs to either use head gradient inserts (obviously limiting the use to the head or foot) or one may relax the linearity of the gradient field and gain better performance with respect to PNS and peak gradient fields, as being done for the NIH Connectome project [83]. For that particular purpose, two dedicated gradient systems have been designed, built and installed [84] allowing either 100 $\mathrm{mT} / \mathrm{m}$ peak gradients at SR 200 (installed at the Mallinckrot Institute in St. Louis, MS) or $300 \mathrm{mT} / \mathrm{m}$ at SR 200 (installed 

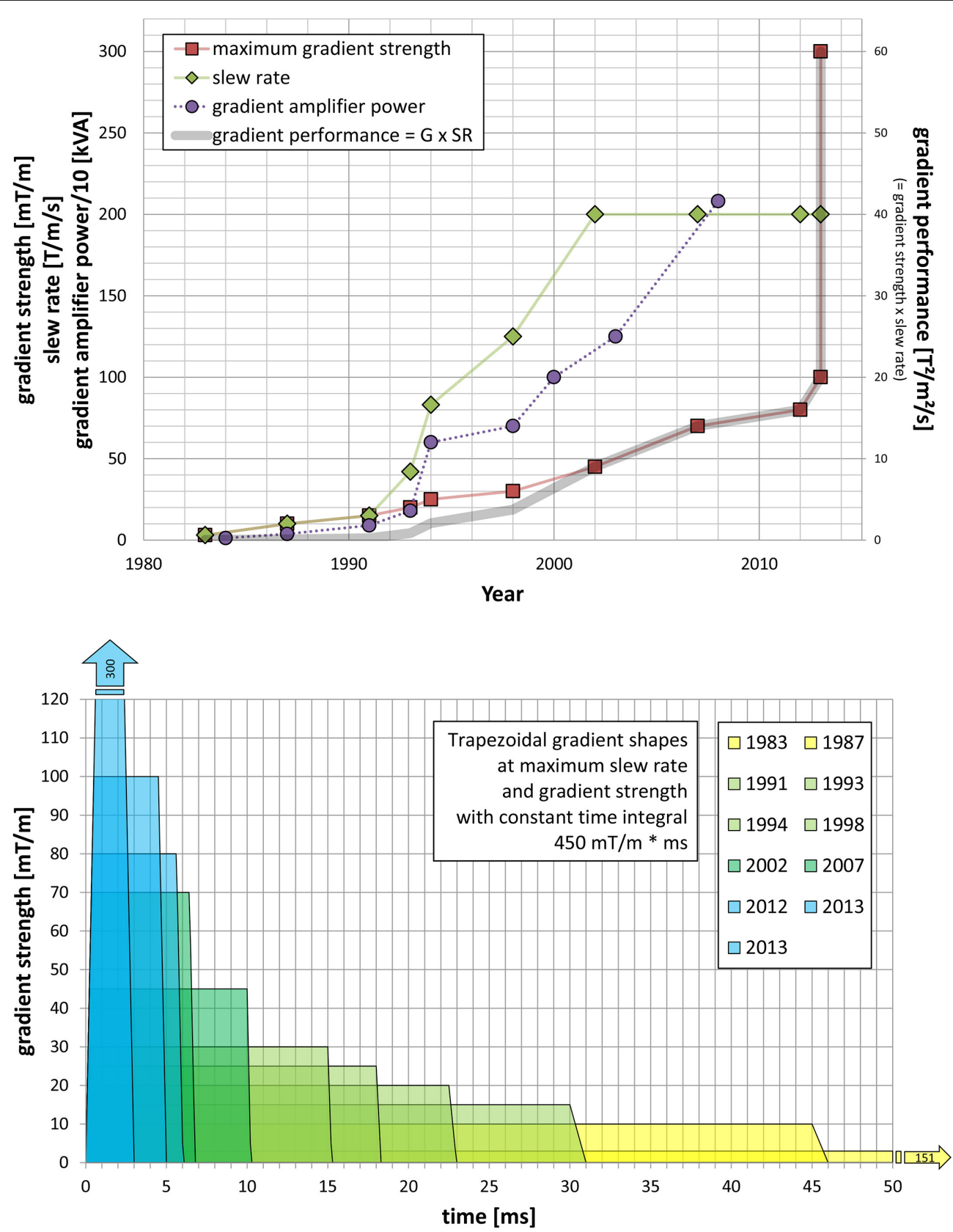

FIGURE 4 | (A) Shows the development of gradient coils for human MRS and MRI research and clinical diagnostics in terms of maximum gradient strength $(\mathrm{mT} / \mathrm{m}$, red) and slew rate (T/m/s, green), as well as gradient amplifier power development (left $y$-axis, purple). The product of maximum gradient strength and slew rate is the gradient performance (right y-axis, thick gray line). (B) Development of trapezoidal gradient shapes at maximum slew rate and gradient strength with constant time integral of $450 \mathrm{mT} / \mathrm{m}^{*} \mathrm{~ms}$, plus equivalent triangular gradient shape, i.e., without plateau time at the maximum gradient strength, for the strongest gradient available at a certain time.

at the A.A. Martinos Center in Charlestown, MA, USA). These strong gradients are particularly used in diffusion-weighted MRI research, revealing e.g., structure and distortions of white matter tracts in the brain [85]. When looking back at the development of gradient performance over the years, it is quite remarkable what has been achieved, i.e., an improvement better than Moore's law as can be seen in Figure 4, also including dedicated research systems like the Connectome scanners. Nevertheless, due to human physiology (PNS) no further increase in SR is possible for whole-body MRI (Figure 4B).

\section{CONCLUSION}

To summarize, for basic research in all three fields, and money not being a severe limitation, i.e., NMR, preclinical and human 
MRI and MRS, higher $B_{0}$ are advantageous for research (up to known physiological limits) but not routinely required. In terms of human MRI and MRS, based on current sc-materials, technology and costs, it might be feasible to build a $14 \mathrm{~T} / 83 \mathrm{~cm}$ magnet. As we cannot expect to further increase slew rates, also gradient coils for human use are operating at a limit. Thus, it would be best to put scientific effort into the development and optimization of novel rf-coils and phased-arrays also reducing noise sources to further push net SNR gain.

At the end of this review, we would like to modify a question posed by Nobel laureate Richard R. Ernst, one of the most proliferate contributors to the success of NMR and MRI: "Why just NMR? - "Why all the fuzz?"

Why just NMR?-Because there is hardly another technique that is so informative for so many different types of applications, and because there is no other technique that provides so much fun. [86]

Why all the fuzz?-Because NMR research over more than 90 years has clearly demonstrated that scientific challenges drive technology, drives research.

In this particular case, due to the persisting quest of ingenious scientists and engineers, we got an extremely versatile tool at hand, providing physicists, chemists, biochemists, researchers in life sciences and medicine, clinicians, but also nutritional chemists and well loggers, with multi-parametric information obtainable non-invasively about water and fat content, molecular motion, structure, dynamics, flow, perfusion, blood oxygenation, diffusion, susceptibility, various metabolites, from atoms and molecules to man-and down to molecular structure and dynamics in liquids, semi-solids (e.g., living tissue), and even solids.

Since ancient times physicists and engineers helped to develop novel methods and technologies to support medical diagnosis and therapy [87].

Keep going and enjoy-for more than another decade!

\section{REFERENCES}

1. Lazarev B, Schubnikov LV. Magnetic moment of a proton. Phys Zeitsch der Sow (1937) 11:445-57.

2. Espy M, Matlashov A, Volegov P. SQUID-detected ultra-low field MRI. J Magn Reson. (2013) 229:127-41. doi: 10.1016/j.jmr.2013. 02.009

3. Lee SK, Mößle M, Myers W, Kelso N, Trabesinger AH, Pines A, et al. SQUIDdetected MRI at $132 \mu \mathrm{T}$ with T1-weighted contrast established at $10 \mu \mathrm{T}-300$ mT. Magn Reson Med. (2005) 53:9-14. doi: 10.1002/mrm.20316

4. Schneider-Muntau HJ. High field NMR magnets. Solid State Nucl Magn Reson. (1997) 9:61-71. doi: 10.1016/S0926-2040(97)00044-1

5. Gan Z, Kwak H-T, Bird M, Cross T, Gor'kov P, Brey W, et al. High-field NMR using resistive and hybrid magnets. J Magn Reson. (2008) 191:135-40. doi: 10.1016/j.jmr.2007.12.008

6. Bird MD, Dixon IR, Toth J. Large, high-field magnet projects at the NHMFL. IEEE Trans Appl Supercond. (2015) 25:1-6. doi: 10.1109/TASC.2014.2367470

7. Wilson MN. Superconducting Magnets. Oxford, UK: Clarendon (1983).

8. Bloch F, Hansen WW, Packard M. Nuclear induction. Phys Rev. (1946) 69:127. doi: 10.1103/PhysRev.69.127

9. Ernst RR. Zurich's contributions to 50 years development of bruker. Angew Chemie Int Ed. (2010) 49:8310-5. doi: 10.1002/anie.201005067

\section{AUTHOR CONTRIBUTIONS}

EM conceived the topic, collected the data and prepared the original manuscript. EL helped preparing the manuscript and prepared the figures. FS collected data and helped preparing the manuscript. GK critically revised the manuscript. All authors participated in manuscript review.

\section{ACKNOWLEDGMENTS}

As all history has no clear cut beginning and no end to be seen in the mist of time, we should be aware that an attempt to pick out a few aspects is prone to error. This being said, we would like to thank the many colleagues and friends who helped with additional information. However, all errors or omissions are due to our own limitations. Particularly, we would like to thank M. D. Bird (Tallahassee, FL, USA), C. Boesch (Bern, $\mathrm{CH}$ ), A. Heerschap (Nijmegen, NL), P.R. Luijten (Utrecht, NL), M. Ilg, C. Oerther, P. Wikus, and G. Roth (Ettlingen, DE), P. A. Rinck (Sophia Antipolis, F), L. Soellner and M. Blasche (Erlangen, DE), S. Pittard, D. L. Rayner, and R. Warner (Oxford, $\mathrm{UK})$. EM dedicates this review to the memory of his mentors, Britton Chance and John S. "Jack" Leigh (Philadelphia, PA, USA). Partly supported by the Austrian BMWFJ FFG Project 832107 Research Studio for Ultra-High Field MR Applications; EM acknowledges an unrestricted research grant by Siemens Healthineers (Erlangen, Germany). The funding sources had no influence on the scientific scope nor the outcome of this study.

\section{SUPPLEMENTARY MATERIAL}

The Supplementary Material for this article can be found online at: http://journal.frontiersin.org/article/10.3389/fphy. 2017.00033/full\#supplementary-material
10. Freeman R, Morris GA. The varian story. J Magn Reson. (2015) 250:80-4.

11. Lauterbur PC. Image formation by induced local interactions. Examples employing nuclear magnetic resonance. Nature (1973) 242:190-1.

12. Becker ED. A brief history of nuclear magnetic resonance. Anal Chem. (1993) 65:295A-302A. doi: 10.1021/ac00054a001

13. Bratton CB, Hopkins AL, Weinberg JW. Nuclear magnetic resonance studies of living muscle. Science (1965) 147:738-9. doi: 10.1126/science.147.3659.738

14. Jackson JA, Langham WH. Whole-body NMR spectrometer. Rev Sci Instrum. (1968) 39:510-3.

15. Yntema GB. Superconducting winding for electromagnets. Phys Rev. (1955) 98:1197.

16. Berlincourt TG, Hake RR. Pulsed-magnetic-field studies of superconducting transition metal alloys at high and low current densities. Bull Am Phys Soc. (1962) II:408.

17. Cheng-ren L, Xiao-zu W, Nong Z. Nb-Ti superconducting composite with high critical current density. IEEE Trans Magn. (1983) 19:284-7. doi: 10.1109/TMAG.1983.1062365

18. Wilson MN. A century of superconducting technology. AIP Conf Proc 1435 (2012) 11:11-35. doi: 10.1063/1.4712077

19. Ernst RR, Anderson WA. Application of Fourier transform spectroscopy to magnetic resonance. Rev Sci Instrum. (1966) 37:93-102. doi: $10.1063 / 1.1719961$ 
20. Ernst RR. The advent of NMR in the light of Sir Peter Mansfield's innovations. MAGMA (1999). 9:97-99.

21. Hahn EL, Mansfield P. NMR and MRI in Retrospect [and Discussion]. Philos Trans $R$ Soc A Math Phys Eng Sci. (1990) 333:403-11. doi: 10.1098/rsta.1990.0168

22. Rinck PA. Magnetic Resonance in Medicine. The Basic Textbook of the European Magnetic Resonance Forum, 11th Edn. E-version 11.1 beta. (2017).

23. Hinshaw WS, Bottomley PA, Holland GN. Radiographic thin-section image of the human wrist by nuclear magnetic resonance. Nature (1977) 270:722-3. doi: $10.1038 / 270722 \mathrm{a} 0$

24. Mansfield P, Maudsley AA. Medical imaging by NMR. Br J Radiol. (1977) 50:188-94. doi: 10.1259/0007-1285-50-591-188

25. Mansfield P, Pykett IL, Morris PG, Coupland RE. Human whole body line-scan imaging by NMR. Br J Radiol. (1978) 51:921-2. doi: 10.1259/0007-1285-51-611-921

26. Morris P. Morris, Peter: whole-body MRI in nottingham: the first steps. In: Grant DM, Harris RK editors. Encyclopedia of Magnetic Resonance. Chichester: John Wiley \& Sons, Ltd. (2012). p. 1-6.

27. Odeblad E, Lindström G. Some preliminary observations on the proton magnetic resonance in biologic samples. Acta Radiol. (2008) 49:57-61. doi: 10.1080/02841850802133337

28. Rooney WD, Johnson G, Li X, Cohen ER, Kim SG, Ugurbil K, et al. Magnetic field and tissue dependencies of human brain longitudinal $1 \mathrm{H} 2 \mathrm{O}$ relaxation in vivo. Magn Reson Med. (2007) 57:308-18. doi: 10.1002/mrm. 21122

29. Koenig SH, Brown RD. Relaxometry of tissue. In: Grant DM, Harris RK editors. Encyclopedia of Magnetic Resonance. Chichester: John Wiley \& Sons, Ltd. (2007). doi: 10.1002/9780470034590.emrstm0466

30. Holzmueller P, Reckendorfer H, Burgmann H, Moser E. Viability testing of transplantation donor liver bylH NMR relaxometry. Magn Reson Med. (1990) 16:173-8. doi: 10.1002/mrm.1910160117

31. Moser E, Holzmueller P, Reckendorfer H, Burgmann H. Cold-preserved rat liver viability testing by proton nuclear magnetic resonance relaxometry. Transplantation (1992) 53:536-9.

32. Kleinberg RL, Jackson JA. An introduction to the history of NMR well logging. Concepts Magn Reson. (2001) 13:340-2. doi: 10.1002/cmr.1018

33. Damadian RV, Chu D. The possible role of cranio-cervical trauma and abnormal CSF hydrodynamics in the genesis of multiple sclerosis. Physiol Chem Phys Med NMR (2011) 41:1-17.

34. Huber C, Abert C, Bruckner F, Groenefeld M, Muthsam O, Schuschnigg S, et al. $3 \mathrm{D}$ print of polymer bonded rare-earth magnets, and $3 \mathrm{D}$ magnetic field scanning with an end-user 3D printer. Appl Phys Lett. (2016) 109:162401. doi: $10.1063 / 1.4964856$

35. Fan TW-M, Lane AN. Applications of NMR spectroscopy to systems biochemistry. Prog Nucl Magn Reson Spectr. (2016) 92-3:18-53. doi: 10.1016/j.pnmrs.2016.01.005

36. Bhattacharya A. Breaking the billion-hertz barrier. Nat News Featur. (2010) 463:605-6. doi: 10.1038/463605a.

37. Ardenkjaer-Larsen J-H, Boebinger GS, Comment A, Duckett S, Edison AS, Engelke F, et al. Facing and overcoming sensitivity challenges in biomolecular NMR spectroscopy. Angew Chemie Int Ed. (2015) 54:9162-5. doi: 10.1002/anie.201410653

38. Gordon RE, Hanley PE, Shaw D, Gadian DG, Radda GK, Styles P, et al. Localization of metabolites in animals using 31P topical magnetic resonance. Nature (1980) 287:736-8.

39. Bottomley PA, Kogure K, Namon R, Alonso OF. Cerebral energy metabolism in rats studied by phosphorus nuclear magnetic resonance using surface coils. Magn Reson Imaging (1982) 1:81-5.

40. Koretsky AP, Wang S, Murphy-Boesch J, Klein MP, James TL, Weiner MW. 31P NMR spectroscopy of rat organs, in situ, using chronically implanted radiofrequency coils. Proc Natl Acad Sci USA (1983) 80:7491-5.

41. Evanochko WT, $\mathrm{Ng} \mathrm{TC}$, Glickson JD. Application of in vivo NMR spectroscopy to cancer. Magn Reson Med. (1984) 1:508-34.

42. Balaban RS, Gadian DG, Radda GK. Phosphorus nuclear magnetic resonance study of the rat kidney in vivo. Kidney Int. (1981) 20:575-9. doi: 10.1038/ki.1981.179

43. Iles RA, Griffiths JR. Hepatic metabolism by 31P NMR. Biosci Rep. (1982) 2:735-42. doi: 10.1007/BF01114837
44. Ingwall JS. Phosphorus nuclear magnetic resonance spectroscopy of cardiac and skeletal muscles. Am J Physiol. (1982) 242:H729-44.

45. Heerschap A, Sommers MG, Zandt HJA, Renema WKJ, Veltien AA, Klomp DWJ. Nuclear magnetic resonance in laboratory animals. In: Conn PM editor. Methods in Enzymology, Vol. 385. Cambridge, MA: Elsevier (2004). p. 41-63.

46. Marzola P, Osculati F, Sbarbati A. High field MRI in preclinical research. Eur J Radiol. (2003) 48:165-70. doi: 10.1016/j.ejrad.2003.08.007

47. Darrasse L, Ginefri J-C. Perspectives with cryogenic RF probes in biomedical MRI. Biochimie (2003) 85:915-37. doi: 10.1016/j.biochi.2003.09.016

48. Houpt TA, Cassell JA, Riccardi C, DenBleyker MD, Hood A, Smith JC. Rats avoid high magnetic fields: dependence on an intact vestibular system. Physiol Behav. (2007) 92:741-7. doi: 10.1016/j.physbeh.2007.05.062

49. Wells PN. Physics and engineering: milestones in medicine. Med Eng Phys. (2001) 23:147-53. doi: 10.1016/S1350-4533(01)00042-X

50. Cady EB, Joan Dawson M, Hope PL, Tofts PS, De L. Costello AM, et al. Non-invasive investigation of cerebral metabolism in newborn infants by phosphorus nuclear magnetic resonance spectroscopy. Lancet (1983) 321:1059-62. doi: 10.1016/S0140-6736(83)91906-2

51. Hope PL. Cerebral energy metabolism studied with phosphorus NMR spectroscopy in normal and birth-asphyxiated infants. Lancet (1984) 324:366-70. doi: 10.1016/S0140-6736(84)90539-7

52. Chance B, Eleff S, Leigh JS, Sokolow D, Sapega A. Mitochondrial regulation of phosphocreatine/inorganic phosphate ratios in exercising human muscle: a gated 31P NMR study. Proc Natl Acad Sci USA. (1981) 78:6714-8.

53. Radda GK, Bore PJ, Gadian DG, Ross BD, Styles P, Taylor DJ, MorganHughes J. 31P NMR examination of two patients with NADH-CoQ reductase deficiency. Nature (1982) 295:608-9. doi: 10.1038/295608a0

54. Radda G. The use of NMR spectroscopy for the understanding of disease. Science (1986) 233:640-5. doi: 10.1126/science.3726553

55. Ertürk MA, Wu X, Eryaman Y, Van de Moortele PF, Auerbach EJ, Lagore RL, et al. Toward imaging the body at 10.5 tesla. Magn Reson Med. (2017) 77:434-43. doi: $10.1002 / \mathrm{mrm} .26487$

56. Lvovsky Y, Stautner EW, Zhang T. Novel technologies and configurations of superconducting magnets for MRI. Supercond Sci Technol. (2013) 26:93001. doi: 10.1088/0953-2048/26/9/093001

57. Moser E. Ultra-high-field magnetic resonance: why and when? World J Radiol. (2010) 2:37-40. doi: 10.4329/wjr.v2.i1.37

58. Moser E, Stahlberg F, Ladd ME, Trattnig S. 7T MR - from research to clinical applications? NMR Biomed. (2012) 25:695-716. doi: 10.1002/nbm.1794

59. Robitaille PM, Warner R, Jagadeesh J, Abduljalil AM, Kangarlu A, Burgess RE, et al. Design and assembly of an 8 tesla whole-body MR scanner. J Comput Assist Tomogr. (1999) 23:808-20.

60. Vaughan JT, Garwood M, Collins CM, Liu W, DelaBarre L, Adriany G, et al. $7 \mathrm{~T}$ vs. 4T: RF power, homogeneity, and signal-to-noise comparison in head images. Magn Reson Med. (2001) 46:24-30. doi: 10.1002/mrm.1156

61. Warner R. Ultra-high field magnets for whole-body MRI. Supercond Sci Technol. (2016) 29:94006. doi: 10.1088/0953-2048/29/9/094006

62. Webb AG, Van de Moortele PF. The technological future of 7 T MRI hardware. NMR Biomed. (2016) 29:1305-15. doi: 10.1002/nbm.3315

63. Zwanenburg JJM, van der Kolk AG, Luijten PR. Ultra-high-field MR imaging. PET Clin. (2013) 8:311-28. doi: 10.1016/j.cpet.2013.03.004

64. Pruessmann KP, Weiger M, Scheidegger MB, Boesiger P. SENSE: sensitivity encoding for fast MRI. Magn Reson Med. (1999) 42:952-62.

65. Griswold MA, Jakob PM, Heidemann RM, Nittka M, Jellus V, Wang J, et al. Generalized autocalibrating partially parallel acquisitions (GRAPPA). Magn Reson Med. (2002) 47:1202-10. doi: 10.1002/mrm.10171

66. Ugurbil K, Adriany G, Andersen P, Chen W, Garwood M, Gruetter R, et al. Ultrahigh field magnetic resonance imaging and spectroscopy. Magn Reson Imaging (2003) 21:1263-81. doi: 10.1016/j.mri.2003.08.027

67. Duyn JH. The future of ultra-high field MRI and fMRI for study of the human brain. Neuroimage (2012) 62:1241-8. doi: 10.1016/j.neuroimage.2011.10.065

68. Tretkoff E. This Month in Physics History. July, 1977: MRI uses fundamental physics for clinical diagnosis. Am Phys Soc News (2006) 15. Available online at: http://www.aps.org/publications/apsnews/200607/history.cfm

69. Freeman R, Morris GA. The Varian story. J Magn Reson (2015) 250:80-4 doi: 10.1016/j.jmr.2014.12.001

70. Budinger TF. MR safety: past, present, and future from a historica perspective. Magn Reson Imaging Clin N Am. (1998) 6:701-14. 
71. Kangarlu A, Burgess RE, Zhu H, Nakayama T, Hamlin RL, Abduljalil AM, et al. Cognitive, cardiac, and physiological safety studies in ultra high field magnetic resonance imaging. Magn Reson Imaging (1999) 17:1407-16. doi: 10.1016/S0730-725X(99)00086-7

72. Chakeres DW, de Vocht F. Static magnetic field effects on human subjects related to magnetic resonance imaging systems. Prog Biophys Mol Biol. (2005) 87:255-65. doi: 10.1016/j.pbiomolbio.2004. 08.012

73. Feychting M. Health effects of static magnetic fields-a review of the epidemiological evidence. Prog Biophys Mol Biol. (2005) 87:241-6. doi: 10.1016/j.pbiomolbio.2004.08.007

74. Schenck JF. Physical interactions of static magnetic fields with living tissues. Prog Biophys Mol Biol. (2005) 87:185-204. doi: 10.1016/j.pbiomolbio.2004.08.009

75. Cavin ID, Glover PM, Bowtell RW, Gowland PA. Thresholds for perceiving metallic taste at high magnetic field. J Magn Reson Imaging (2007) 26:1357-61. doi: 10.1002/jmri.21153

76. Glover PM, Cavin I, Qian W, Bowtell R, Gowland PA. Magnetic-field-induced vertigo: a theoretical and experimental investigation. Bioelectromagnetics (2007) 28:349-61. doi: 10.1002/bem.20316

77. Heilmaier C, Theysohn JM, Maderwald S, Kraff O, Ladd ME, Ladd SC. A large-scale study on subjective perception of discomfort during 7 and 1.5 T MRI examinations. Bioelectromagnetics (2011) 32:610-9. doi: $10.1002 /$ bem. 20680

78. Roberts DC, Marcelli V, Gillen JS, Carey JP, Della Santina CC, Zee DS, et al. MRI magnetic field stimulates rotational sensors of the brain. Curr Biol. (2011) 21:1635-40. doi: 10.1016/j.cub.2011.08.029

79. Springer E, Dymerska B, Cardoso PL, Robinson SD, Weisstanner C, Wiest $\mathrm{R}$, et al. Comparison of routine brain imaging at $3 \mathrm{~T}$ and 7 T. Invest Radiol. (2016) 51:469-82. doi: 10.1097/RLI.000000000 0000256
80. Thormann M, Amthauer H, Adolf D, Wollrab A, Ricke J, Speck O. Efficacy of diphenhydramine in the prevention of vertigo and nausea at 7T MRI. Eur J Radiol. (2013) 82:768-72. doi: 10.1016/j.ejrad.2011.08.001

81. Schenck JF, Dumoulin CL, Redington RW, Kressel HY, Elliott RT, McDougall IL. Human exposure to 4.0-Tesla magnetic fields in a whole-body scanner. Med Phys. (1992) 19:1089-98. doi: 10.1118/1.596827

82. Wijnen JP, Klomp DWJ. Advances in magnetic resonance spectroscopy. PET Clin. (2013) 8:237-44. doi: 10.1016/j.cpet.2013.03.001

83. Van Essen DC, Ugurbil K, Auerbach E, Barch D, Behrens TE, Bucholz R, et al. The human connectome project: a data acquisition perspective. Neuroimage (2012) 62:2222-31. doi: 10.1016/j.neuroimage.2012.02.018

84. Kimmlingen R, Eberlein E, Dietz P, Kreher S, Schuster J, Riegler J. et al. Concept and realization of high strength gradients for the Human Connectome Project. Proc Intl Soc Mag Reson Med. (2012) 11:63194.

85. Van Essen DC, Smith SM, Barch DM, Behrens TEJ, Yacoub E, Ugurbil K. The WU-Minn human connectome project: an overview. Neuroimage (2013) 80:62-79. doi: 10.1016/j.neuroimage.2013.05.041

86. Ernst RR. Why just NMR? Isr J Chem. (1992) 32:135-6. doi: 10.1002/ijch.199200019

87. Keevil SF, Duke T, Nunes A, Parisi A. Physics and medicine: a historical perspective. Lancet (2012) 379:1517-24. doi: 10.1016/S0140-6736(11)60282-1

Conflict of Interest Statement: FS is a retired employee of Siemens Healthcare. All other authors declare no conflict of interest.

Copyright (c) 2017 Moser, Laistler, Schmitt and Kontaxis. This is an open-access article distributed under the terms of the Creative Commons Attribution License (CC $B Y)$. The use, distribution or reproduction in other forums is permitted, provided the original author(s) or licensor are credited and that the original publication in this journal is cited, in accordance with accepted academic practice. No use, distribution or reproduction is permitted which does not comply with these terms. 